\title{
ANALISIS PERBANDINGAN METODE DEMPSTER SHAFER DAN CERTAINTY FACTOR PADA SISTEM PAKAR UNTUK DIAGNOSIS PENYAKIT DAN HAMA TANAMAN KAKAO
}

\author{
Elvisiana Bapu \\ Program Studi Teknik Informatika S1, Fakultas Teknologi Industri \\ Institut Teknologi Nasional Malang, Jalan Raya Karanglo km 2 Malang, Indonesia \\ 1518057_Penulis@scholar.itn.ac.id
}

\begin{abstract}
ABSTRAK
Kurangnya prngrtahuan petani tentang hama dan penyakit kakao di Daerah Ende Desa Saga Kec.Detusoko Provinsi Nusa Tenggarah timur,mengakibatkan tanaman kakao di tinggalkan begitu saja tanpa adanya penangulangan dari Pemerintah hal ini sisebabkan oleh kurangnya penyuluhan pengetahuan bagimana bercocok tanam kakao yang baik oleh pamarintah setempat,sehingga membuat penulis ingin memberikan solusi unruk memperbaiki kondisi ini,perkembangan pengetahuan system pakar dapat membantu menyelesaikan masalah tersebut.proses pembuatan system pakar berawalanan dari pencarian data tentang penyakit dan hama tanaman kakao,yang di peroleh dari BPTP Jawa Timur,Karangploso yang kemudian di validasi oleh ahli hama dan penyakit tanmana yaitu Bapak Ir.Handoko,Msc dalam penelitian ini,proses system pakar mengunakan dua metode yaitu Demspter Shafer Dan Certainty Faktor hasilnya dari pengunaan kedua metode tersebut di bandingkan dan hasil menunjukan bahwa Dempster Shafer lebih unggul daripada Certainty Faktor.
\end{abstract}

Kata kunci : System Pakar, Hama dan Penyakit kakao,Dempster Shafer,Certainty Faktor, Web

\section{PENDAHULUAN}

\subsection{Latar Belakang}

Penyakit merupakan tanama yang dapat menghambat dan merusak,pertumbuhan tanaman,penyakit ini di kenali melalui gejalagejala pada tanaman yang terserang pertumbuhan penyakit pada tanaman akan mengakibatkan kerugian untuk para petani terutamanya,sedangkan hama pada tanaman segala jenis hewan yang berpostensi menganngu pertumbuhan pada tanaman yang menyebabkan pada hasil panen nantinya atau para petani akan mengalami kegagalan panen yang sangat merugikan.

Analisa perbandinagan metode hasil diagnosis hama dan penyakit di laukan dengan 2 metode yang berbeda yaitu Dempster Shafer dan Certainty Faktor, dimana digunakan pada jenis hama dan penyakit kakao yang mempunyai gejala penyakit yang berbeda. Pada aplikasi system pakar hama dan penyakit tanaman kakao terdapat sejumlah edivance yang digunakan pada factor ketidakpastian dalam pengambilan keputusan untuk mendiagnosis hama dan penyakit kakao, cara untuk mengatasi sejumlah edivance untuk Dempster shafe.sedangkan certainty factor adalah teori untuk mengakomedasikan ketidak pastian pemikiran (inexact reasoning) seorang pakar.

Permasalahan yang sering terjadi dikarenakan rendah perodukvitas tanaman kakao dan mutu yang di sebabkan berapa hal di antaranya benih yang di gunakan beragam lokal dan pemiliharan yang di lakukan masih seadanya dan belum melakukan permentasi sebagai faktor penentuan mutuh kakao dan adanya masalah yang paling utama adalah kurangnya pengtahuan dan kenterampilan dalam membududayakan tanaman kakao, sehingga para petani tidak mengtahui hama dan penyakit yang sedang terserang pada tanaman kakao.

\subsection{Rumusan Masalah}

Berdasarkan latar belakang yang telah dikemukakan sebelumnya, maka penulis merumuskan masalah yang akan dibahas sebagai berikut :

1. Bagimana membuat aplikasi system pakar berbasis Website.?

2. Bagimana membuat system pakar untuk mendiagnosis hama dan penyakit pada tanamana kakao (Theobroma Cacao L).?

3. Bagimana mendiagnosis peyakit dan hama pada metode Dempster Shafer.?

4. Bagimana mendiagnosis hama dan penyakit mengunakan metode Certainty Faktor.?

5. Bagimana membandingkan Dempster Shafer dan Certainty Faktor pada aplikasi system pakar.?

6. Bagimana menentukan mesin Inferensi (mesin Penelusuran) pada aplikasi system pakar.? 


\subsection{Batasan Masalah}

Dalam penyusunan skripsi agar menjadi sistematis dan mudah dimengerti, maka akan diterapkan beberapa batasan masalah, antara lain :

1. Jenis penyakit pada tanaman kakao (Theobroma Cacao L) sejumlah 8 penyakit dengan gejala penyakit sejumlah 30 gejala penyakit.

2. Jenis hama pada tanaman kakao (Theobroma Cacao L) sejumlah delapan hama dengan 20 gejala.

3. User pada aplikasi system pakar untuk diagnosis untuk diagnosis penyakit dan hama tanaman kakao (Theobroma Cacao L) adalah user (petani) dan admin (pakar).

\subsection{Tujuan}

Adapun yang menjadi tujuan penulisan dalam penyusunan penelitian skripsi adalah sebagai berikut :

1. Aplikasi sistem pakar dibangun dengan menggunakan bahasa pemrograman $P H P$ dengan database $M y S Q L$.

2. Aplikasi sistem pakar dibangun dengan menggunakan data yang diperoleh dari Balai Pengkajian Teknologi Pertanian Jawa Timur yang berada di Jalan Raya Karanglo KM.4 Kepuharjo Karangploso yang divalidasi oleh Ahli Hama dan Penyakit Tanaman yaitu Bapak Ir. Handoko, MSc.

3. Untuk menentukan jenis penyakit dan hama pada tanaman kakao (Theobroma Cacao L.) digunakan metode Dempster Shafer dan Certainty Factor .

4. Mesin inferensi yang digunakan pada sistem pakar untuk diagnosis sistem pakar penyakit dan hama pada tanaman kakao (Theobroma Cacao L.) adalah forward chaining (alur maju).

\section{TINJAUAN PUSTAKA}

\subsection{Tinjuan Terdahulu}

Penelitian ini dilaksanakan di desa Betung, kecamatan Kumpeh Ilir kabupaten Muaro Jambi dan Laboratorium Universitas Batanghari selama 6 bulan yaitu pada bulan Maret sampai dengan Agustus 2017. Pengambilan sampel tanaman dilakukan secara acak dengan Simple Random Sampling di perkebunan kakao rakyat. Pengamatan dilakukan terhadap tanaman kakao dengan menghitung seluruh buah baik yang sehat maupun yang sakit sehingga didapat persentase buah kakao yang terserang. .Tanaman kakao yang diamati adalah yang menunjukkan gejala serangan jamur Phytopthora palmivora. Gejala serangan penyakit busuk buah adalah timbulnya bercakbercak hitam pada bagian kulit luar buah. Bercak-bercak hitam itu akan meluas hingga menutupi semua bagian kulit buah. Buah yang busuk diambil dan dibungkus dengan kertas koran lembab dan masukkan ke dalam kantong plastik, kemudian dibawa ke laboratorium dan disimpan dalam alat pendingin sampai saatnya untuk diidentifikasi. Pengamatan yang dilakukan di lapangan terhadap tanaman kakao adalah dengan menghitung tanaman dan buah kakao yang ada pada tanaman sampel, baik yang terserang maupun tidak terserang.[1]

Penelitian ini dilaksanakan pada bulan Maret sampai Agustus 2016 di Laboratorium Jurusan Biologi Unit Bioteknologi FMIPA Untad. penelitian ini adalah ranting tanaman kakao yang terinfeksi jamur $\mathrm{O}$. Theobromae yang diperoleh dari perkebunan Rakyat Desa Makmur, Kecamatan Palolo, Kabupaten Sigi, Propinsi Sulawesi Tengah, media Potato Sukrosa Agar (PSA), aquades steril, alkohol 70\%, kertas tissue, dan methylene blue. Pengembangan kakao di daerah ini, tidak lepas dari berbagai hambatan. Salah satu hambatan yang ada adalah masalah gangguan penyakit. Penyakit utama pada tanaman kakao adalah penyakit Vascular Streak Dieback (VSD).[2]

\subsection{Sistem pakar}

Sistem pakar adalah suatu program komputer yang dirancang untuk mengambil keputusan seperti keputusan yang diambil oleh seorang atau beberapa orang pakar. Dalam penyusunannya, sistem pakar mengkombinasikan kaidah-kaidah penarikan kesimpulan (inference rules) dengan basis pengetahuan tertentu yang diberikan oleh satu atau lebih pakar dalam bidang tertentu.

Kombinasi dari kedua hal tersebut disimpan dalam komputer, yang selanjutnya digunakan dalam proses pengambilan keputusan untuk penyelesaian masalah tertentu. Tujuan utama sistem pakar bukan untuk menggantikan kedudukan seorang ahli atau pakar, tetapi hanya untuk memasyarakatkan pengetahuan dan pengalaman dari para pakar. Seiring pertumbuhan populasi manusia, maka di masa yang akan datang sistem pakar ini diharapkan sangat berguna membantu dalam hal pengambilan keputusan.

Berikut ini ada beberapa definisi tentang sistem pakar menurut para ahli, antara lain :

a. Sistem pakar (expert system) secara umum adalah sistem yang berusaha mengadopsi pengetahuan manusia ke komputer, agar komputer dapat menyelesaikan masalah seperti yang biasa dilakukan oleh para ahli (Kusumadewi, 2003).

b. Sistem pakar adalah sistem berbasis komputer yang menggunakan pengetahuan, fakta, dan teknik penalaran dalam memecahkan masalah yang biasanya hanya dapat dipecahkan oleh seorang pakar dalam bidang tersebut (Kusrini, 2006).

c. Seorang pakar adalah orang yang mempunyai keahlian dalam bidang tertentu, yaitu pakar yang 
mempunyai knowledge atau kemampuan khusus yang orang lain tidak mengetahui atau mampu dalam bidang yang dimilikinya (Arhami, 2005).

\subsection{Struktur Sistem Pakar}

Sistem pakar disusun oleh dua bagian utama yaitu lingkungan pengembang (development environment) dan lingkungan konsultasi (consultation environment) (Turban, 2005). Lingkungan pengembang sistem pakar digunakan untuk memasukkan pengetahuan ke dalam lingkungan sistem pakar, sedangkan lingkungan konsultasi digunakan oleh pengguna yang bukan pakar guna memperoleh pengetahuan pakar. Arsitektur Sistem Pakar dapat dilihat pada Gambar 2.1.

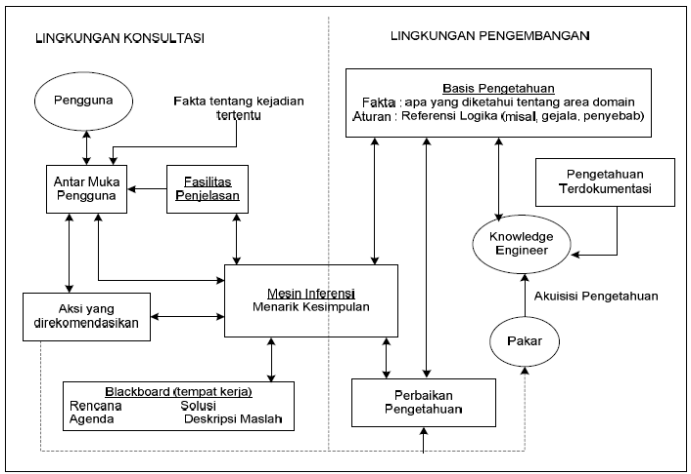

Gambar 2.1 Arsitektur Sistem Pakar.

\subsection{Mesin Inferensi}

Mesin inferensi adalah bagian yang mengandung mekanisme fungsi berfikir dan polapola penalaran sistem yang digunakan oleh seorang pakar. Mekanisme ini menganalisa suatu masalah tertentu dan selanjutnya akan mencari jawaban atau kesimpulan. Mesin inferensi memiliki tiga elemen pokok (Turban, 2005) yaitu :

1. Penerjemah (Interpreter), yang menjalankan pilihan jenis-jenis agenda dengan menerapkan kaidah basis pengetahuan yang ada.

2. Pengaturan (Scheduler), yang mengatur control atas agenda. Penalaran mempengaruhi kaidah inferensi dalam jenis prioritas yang jelas atau kriteria lain di dalam agenda.

3. Kemampuan Penyelesaian (Consistency Enforcer), yang mencoba untuk menjaga ketepatan representasi dari penyelesaian yang muncul. Bagian ini akan berusaha memelihara kekonsistenan dan mempresentasikan solusi yang bersifat darurat.

\subsection{Demspter Shafer}

Ada berbagai macam penalaran dengan model yang lengkap dan sangat konsisten, tetapi pada kenyataannya banyak permasalahan yang tidak dapat terselesaikan secara lengkap dan konsisten. Ketidakkonsistenan yang tersebut adalah akibat adanya penambahan fakta baru.
Penalaran yang seperti itu disebut dengan penalaran non monotonis. Untuk mengatasi ketidakkonsistenan tersebut maka dapat menggunakan penalaran dengan teori DempsterShafer. Secara umum teori Dempster-Shafer ditulis dalam suatu interval [3]:

[Belief,Plausibility].

- Belief (Bel) adalah ukuran kekuatan evidence dalam mendukung suatu himpunan proposisi. Jika bernilai 0 maka mengindikasikan bahwa tidak ada evidence, dan jika bernilai 1 menunjukkan adanya kepastian

- Plausibility (Pl) dinotasikan sebagai : $\mathrm{Pl}(\mathrm{s})$ $=1-\operatorname{Bel}(-\mathrm{s}) \quad$ Plausibility juga bernilai sampai 1. Jika yakin akan $-\mathrm{s}$, maka dapat dikatakan bahwa $\operatorname{Bel}(-\mathrm{s})=1$, dan $\mathrm{Pl}\left({ }^{-\mathrm{s}}\right)=0$.

- Pada teori Dempster-Shafer dikenal adanya frame of discrement yang dinotasikan dengan $\theta$. Frame ini merupakan semesta pembicaraan dari sekumpulan hipotesis.

Tujuannya adalah mengaitkan ukuran kepercayaan elemen-elemen $\theta$. Tidak semua evidence secara langsung mendukung tiap-tiap elemen. Untuk itu perlu adanya probabilitas fungsi densitas (m). Nilai $m$ tidak hanya mendefinisikan elemen-elemen $\theta$ saja, namun juga semua subsetnya. Sehingga jika $\theta$ berisi $n$ elemen, maka subset $\theta$ adalah $\mathrm{n} 2$. Jumlah semua $\mathrm{m}$ dalam subset $\theta$ sama dengan 1 .

Apabila tidak ada informasi apapun untuk memilih hipotesis, maka nilai : $\operatorname{m}\{\theta\}=1,0$ Apabila diketahui $\mathrm{X}$ adalah subset dari $\theta$, dengan $\mathrm{m} 1$ sebagai fungsi densitasnya, dan $\mathrm{Y}$ juga merupakan subset dari $\theta$ dengan $\mathrm{m} 2$ sebagai fungsi densitasnya, maka dapat dibentuk fungsi kombinasi $\mathrm{m} 1$ dan $\mathrm{m} 2$ sebagai $\mathrm{m} 3$, yaitu :[3]

$$
\mathrm{m} 3(\mathrm{Z})=\frac{\sum_{X \cap Y=Z} \mathrm{~m}_{1}(\mathrm{X}) \cdot \mathrm{m}_{2}(\mathrm{Y})}{1-\sum_{\mathrm{X} \cap Y=\emptyset} \mathrm{ml}(\mathrm{X}) \cdot \mathrm{m} 2(\mathrm{Y})}, .[2,3]
$$

\section{Keterangan :}

M3 = desitas untuk gejala pertama

M2 = desitas untuk gejala kedua

M3 = kombinasi dari kedua desitas diatas

$\emptyset=$ semesta pembicaraan dari kumpulan hipotasis $(\mathrm{X}, \mathrm{Y})$

$X$ dan $Y=$ subset dari $Z$

$X^{\prime} d n Y^{\prime}=$ subset dari $\varnothing$

\subsection{Certainty Factor}

Certainty Factor merupakan suatu metode yang digunakan untuk menyatakan kepercayaan dalam sebuah kejadian yang merupakan fakta atau hipotesis berdasarkan bukti atau penilaian pakar. Secara konsep, Certainty Factor (CF) merupakan salah satu teknik yang digunakan untuk mengatasi ketidakpastian dalam pengambilan keputusan. Dalam kasus ini, kita 
harus mengagregasikan nilai CF keseluruhan dari setiap kondisi yang ada [8].

Tahapan dalam mempresentasikan data-data kualitatif :

1) Kemampuan untuk mengekspresikan derajat keyakinan sesuai dengan suatu metode.

2) Kemampuan untuk menempatkan dan mengkombinasikan derajat keyakinan tersebut dalam sistem pakar.

Dalam mengekspresikan derajat keyakinan digunakan suatu nilai yang disebut certainty factor (CF) untuk mengasumsikan derajat keyakinan seorang pakar terhadap suatu data. Berikut merupakan formulasi dasar dari certainty factor.

\section{$\mathrm{CF}[\mathrm{H}, \mathrm{E}]=\mathrm{MB}[\mathrm{H}, \mathrm{E}]-\mathrm{MD}[\mathrm{H}, \mathrm{E}]$}

Untuk mengkombinasikan dua atau lebih aturan, sistem berbasis pengetahuan dengan beberapa aturan, masing-masing darinya menghasilkan kesimpulan yang sama tetapi faktor ketidakpastiannya berbeda. Untuk menghitung CF (keyakinan) dari kesimpulan diperlukan bukti pengkombinasian sebagai berikut:

$$
\begin{gathered}
\mathrm{CF}(\mathrm{R} 1, \mathrm{R} 2)=\mathrm{CF}(\mathrm{R} 1)+[\mathrm{CF}(\mathrm{R} 2)] \times[1- \\
\mathrm{CF}(\mathrm{R} 1)]
\end{gathered}
$$

Jika kita hanya menambahkan CF R1 dan R2, kepastian kombinasinya akan lebih dari 1 memodifikasikan jumlah kepastian melalui penambahan faktor kepastian kedua dan mengakalinya (1 dikurangi faktor kepastian pertama). Jadi, semakin besar CF pertama semakin kecil kepastian penambahan kedua. Tetapi faktor tambahan selalu menambahkan beberapa kepastian. Untuk aturan ketiga yang ditambahkan, dapat digunakan aturan sebagai berikut [9].

$$
\begin{aligned}
& \text { CF }(R 1, R 2, R 3)=C F(R 1, R 2)+[C F(R 3)][1- \\
& \text { CF }(R 1, R 2)]=\text { CF }(R 1, R 2)+C F(R 3)- \\
& {[C F(R 1, R 2)] .[C F(R 3)](3)}
\end{aligned}
$$

Untuk solusi dengan lebih banyak aturan dapat menggunakan persamaan yang secara bertingkat seperti pada persamaan diatas.

\subsection{My SQL}

MySQL adalah salah satu jenis database server yang sangat terkenal. Kepopulerannya disebabkan MySQL menggunakan SQL sebagai bahan dasar untuk mengakses databasenya. Selain itu, MySQL bersifat free pada pelbagai paltform (kecuali pada windows, yang bersifat shareware atau perlu membayar setelah melakukan evaluasi dan memutuskan untuk digunakan dalam keleprluan produksi).

MySQL termasuk jenis RDBMS (Relational Database Management System). Itulah sebabnya istilah seperti tabel, baris, dan kolom digunakan pada MySQL. [8]

\subsection{PhpMyAdmin}

PhpMyAdmin adalah sebuah software yang berbentuk seperti halaman situs yang terdapat pada web server. Fungsi dari halaman ini adalah sebagai pengendali database $M y s q l$ sehingga pengguna Mysql tidak perlu repot untuk menggunakan perintahperintah SQL. Karena dengan adanya halaman ini semua hal tersebut dapat dilakukan dengan hanya meng-klik menu fungsi yang ada pada halaman PhpMyAdmin.

\section{METODE PENELITIAN}

\subsection{Analisa Sistem}

Merupakan suatu kegiatan yang menguraikan seluruh pokok masalah yang ada di dalamnya. Analisa merupakan tahapan awal sebelum masuk ke tahapan perancangan, sedangkan perancangan merupakan hasil dari keseluruhan analisa yang dapat memberikan solusi dalam suatu permasalahan.

\subsection{Kebutuhan Fungsional}

Kebutuhan fungsional merupakan kebutuhan atau fungsi yang harus di miliki oleh sebuah sistem. Dengan dideskripsikan kebutuhan fungsional ini, maka suatu sistem memiliki sebuah target yang harus dipenuhi. Berikut beberapa kebutuhan fungsional sistem yang akan dibuat :

1. Sistem memiliki fasilitas login yaitu login sebagai admin dengan memasukkan username dan password.

2. Jika masuk ke sistem dengan akses sebagai admin, berikut fitur-fitur yang akan ditampilkan :

a. Admin dapat melihat data penyakit dan gejala.

b. Admin dapat mengubah data penyakit dan gejala.

c. Admin dapat menambahkan data penyakit dan gejala.

d. Admin dapat menghapus data penyakit dan gejala.

e. Admin dapat mengubah nilai DS dan $\mathrm{CF}$ berdasarkan gejala.

f. Admin dapat keluar (logout) dari system

\subsection{Karakteristik Pengguna}

Karakteristik pengguna ditentukan untuk menentukan siapa saja yang dapat mengakses sistem yang akan dibangun. Pengguna sistem adalah beberapa orang yang tercantum pada Tabel 3.1.

Tabel 3.1 Tabel Pengguna

\begin{tabular}{|l|l|}
\hline \multicolumn{1}{|c|}{ Kategori } & \multicolumn{1}{c|}{ Tugas } \\
\hline $\begin{array}{l}\text { Admin merupakan } \\
\text { pembuat dan } \\
\text { pengelola sistem. }\end{array}$ & $\begin{array}{l}\text { Mengakses semua } \\
\text { sistem. }\end{array}$ \\
\hline $\begin{array}{l}\text { User merupakan } \\
\text { masyarakat yang } \\
\text { menggunakan sistem. }\end{array}$ & $\begin{array}{l}\text { Hanya mengakses } \\
\text { menu diagnosis dan } \\
\text { melihat tampilan isi } \\
\text { data. }\end{array}$ \\
\hline
\end{tabular}




\subsection{Desain Sistem}

Desain sistem merupakan gambaran dari sistem yang akan di implementasikan menjadi sebuah aplikasi. Adapun desain sistem pada penelitian ini meliputi rancangan struktur menu, flowchart dan perancangan database.

\subsubsection{Struktur Menu Admin}

Rancangan Struktur Menu Admin dapat dilihat pada Gambar 3.1.

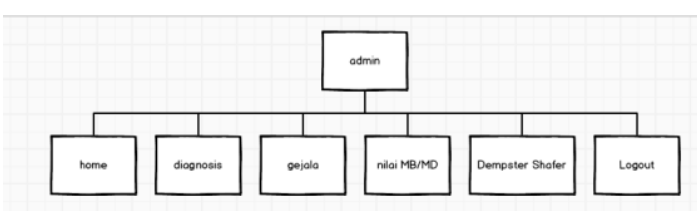

Gambar 3.1 struktur admin

Pada Gambar 3.1 Dalam struktur menu admin terdapat menu home,menu diagnosis,gejala untuk hama dan penyakit,nilai $\mathrm{Md} / \mathrm{Md}$ untuk hama dan penyakit dan nilai dempster shafer untuk hama dan penyakit.

\subsubsection{Struktur Menu User}

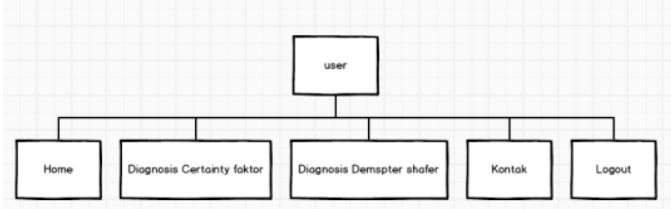

Gambar 3.2 Strukstur user

Pada gambar struktur menu user terdapat menu Diagnosis Dempster Shafer dan Diagnosis Certainty faktor untuk hama dan penyakit,

\subsubsection{Flowchart Admin}

Rancangan Flowchart Admin dapat dilihat pada Gambar 3.3.

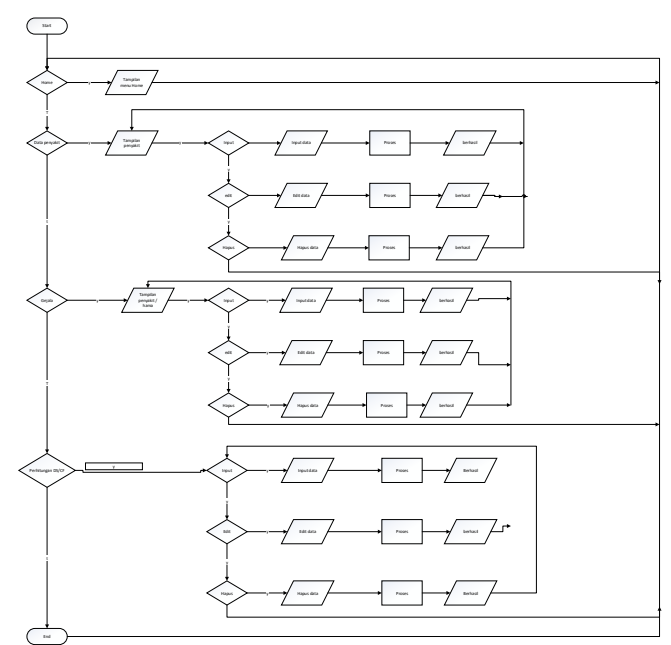

Gambar 3.3 Flowchart Admin
Pada Gamabr 3.3 flowchart admin dapat mengakses data, menambah data,edit data,hapus data dan menambah nilai dempster shafer dan Certainty

\subsubsection{Flowchart User}

Rancangan Flowchart User dapat dilihat pada Gambar 3.4.

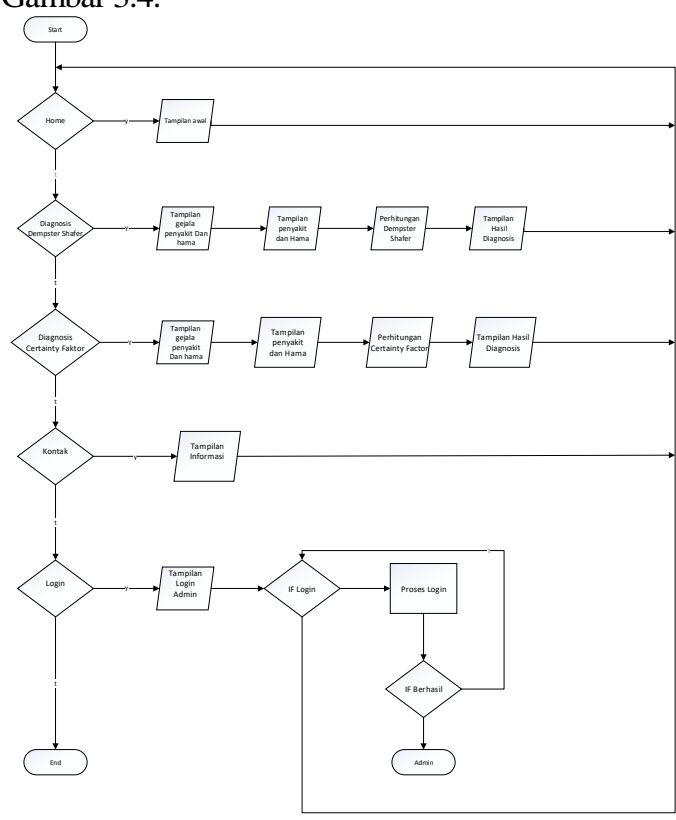

Gambar 3.4 flowchart user

Pada Gambar 3.4 flowchart user,user hanya dapat mengakses table halaman konsultasi, tampilan hasil diagnosis Dempster Shafer dan Certainty factor, halaman kontak User.

\subsubsection{Perancangan Database}

Dalam sistem ini memerlukan sebuah penyimpanan data, dalam program ini penyimpanan datanya menggunakan software XAMPP. Pada database tersebut terdapat beberapa tabel yang digunakan sebagai media penyimpanan data. Tabeltabel tersebut antara lain :

\section{Table penyakit}

\begin{tabular}{|c|c|lc|}
\hline No & $\begin{array}{c}\text { Id } \\
\text { Penyakit }\end{array}$ & \multicolumn{3}{|c|}{ Penyakit } \\
\hline 1. & Idp1 & $\begin{array}{l}\text { Penyakit Busuk Buah Kakao } \\
\text { (Phytophthora Palmivora) }\end{array}$ \\
\hline 2. & Idp2 & $\begin{array}{l}\text { Penyakit Pembuluh Kayu } \\
\text { Oncobasidium Theobromae) }\end{array}$ & (Ppk, \\
\hline 3. & Idp3 & Jamur akar coklat & \\
\hline 4. & Idp4 & Jamur akar Puth & (Upasia \\
\hline 5. & Idp5 & Jamur akar merah & $\begin{array}{l}\text { Penyakit Jamur Upas } \\
\text { salmonicolor) }\end{array}$ \\
\hline 6. & Idp6 & $\begin{array}{l}\text { Penyakit Antraknose (Colletotricum } \\
\text { gloeosporioides Penz. Sacc.) }\end{array}$ \\
\hline 7. & Idp7 dieback \\
\hline 8. & Idp8 & $\begin{array}{l}\text { penyakit vascular streak ditreak dieback } \\
\text { vascular streak } \\
\text { oncobasidium theobromae talbot \& } \\
\text { keane }\end{array}$ \\
\hline
\end{tabular}


tabel penyakit dari tanmana kakao di antaranya id_penyakit dan nama penyakit.

\section{Tabel Hama}

\begin{tabular}{|c|c|l|}
\hline No & $\begin{array}{c}\text { Id } \\
\text { Hama }\end{array}$ & \multicolumn{1}{|c|}{ Hama } \\
\hline 1. & Idh1 & $\begin{array}{l}\text { Pengerek buah } \\
\text { (Conopomorpha cramerella) }\end{array}$ \\
\hline 2. & Idh2 & Kepik pengisap buah (Helopeltis sp) \\
\hline 3. & Idh3 & $\begin{array}{l}\text { Pengerak batang ( zeuzera coffeae } \\
\text { nietn) }\end{array}$ \\
\hline 4. & Idh4 & Kelayuan Pentil (Cherelle Wilt) \\
\hline 5. & Idh5 & Ulat Kilan (Hyposidea Infixaria) \\
\hline 6. & Idh6 & $\begin{array}{l}\text { Ulat Matahari (Parasa lepida dan } \\
\text { Ploneta diducta) }\end{array}$ \\
\hline 7. & Idh7 & Ulat api \\
\hline 8. & Idh8 & Kutu Putih (Pseudococcus Lilacinus) \\
\hline \multicolumn{3}{|c|}{ Tampilan dari tabel hama penyakit di } \\
antaranya id_hama dan nama hama.
\end{tabular}

\section{3. tabel gejala Penyakit}

\begin{tabular}{|c|c|c|c|}
\hline Hama & Gejala & MB & MD \\
\hline G1 & belang kuning atau kuning & 0,6 & 0,2 \\
\hline G2 & terdapat gerakan lubang larva & 0,1 & 0.9 \\
\hline G3 & $\begin{array}{l}\text { bijinya saling melengket dan } \\
\text { kehitaman }\end{array}$ & 0,2 & 0.8 \\
\hline G4 & jika di goyang tdak berbunyi & 0,5 & 0,5 \\
\hline G5 & tampak matang di luar & 0,5 & 0,5 \\
\hline G6 & $\begin{array}{l}\text { bercak cekung berwarna } \\
\text { coklat }\end{array}$ & 0,2 & 0,8 \\
\hline G7 & $\begin{array}{l}\text { menyebabkan buah mati dan } \\
\text { kering }\end{array}$ & 0,7 & 0,3 \\
\hline G8 & $\begin{array}{l}\text { terdapat lubang pada kulit } \\
\text { kayu }\end{array}$ & 0,1 & 0,9 \\
\hline G9 & mengeluarkan sisa serbuk & 0,1 & 0,9 \\
\hline G10 & gugur buah kakao & 0,6 & 0,4 \\
\hline G11 & $\begin{array}{l}\text { serangan terdapat pada pentil } \\
\text { buah kakao }\end{array}$ & 0,25 & 0,75 \\
\hline G12 & $\begin{array}{l}\text { menyerang pada tanaman } \\
\text { muda }\end{array}$ & 0,4 & 0,6 \\
\hline G13 & tanaman menjadi gundul & 0,25 & 0.75 \\
\hline G14 & mnyerang daun muda & 0,4 & 0,6 \\
\hline G15 & $\begin{array}{l}\text { menyerang daun muda dan } \\
\text { buah muda kakao }\end{array}$ & 0,4 & 0,6 \\
\hline G16 & daun berubah menjadi kuning & 0,6 & 0,4 \\
\hline G17 & daunya kakao rontok & 0,35 & 0,75 \\
\hline G18 & menyerang buah kakao kecil & 0,2 & 0,8 \\
\hline G19 & $\begin{array}{l}\text { serangan mulai dari pangkal } \\
\text { buah kakao }\end{array}$ & 0,8 & 0,2 \\
\hline G20 & buah kering dan mati & 0,25 & 0,75 \\
\hline
\end{tabular}

Tabel gejala penyakit yang di antara id_gejala dan gejala penyakit.

\section{Tabel gejala Hama}

\begin{tabular}{|c|c|l|}
\hline No & $\begin{array}{c}\text { Id } \\
\text { Gejala }\end{array}$ & \multicolumn{1}{|c|}{ Gejala } \\
\hline 1. & G1 & belang kuning atau kuning \\
\hline 2. & G2 & terdapat gerakan lubang larva \\
\hline 3. & G3 & $\begin{array}{l}\text { bijinya saling melengket dan } \\
\text { kehitaman }\end{array}$ \\
\hline 4. & G4 & jika di goyang tdak berbunyi \\
\hline 5. & G5 & tampak matang di luar \\
\hline 6. & G6 & bercak cekung berwarna coklat \\
\hline 7. & G7 & menyebabkan buah mati dan kering \\
\hline 8. & G8 & terdapat lubang pada kulit kayu \\
\hline 9. & G9 & mengeluarkan sisa serbuk \\
\hline 10. & G10 & gugur buah kakao \\
\hline 11. & G11 & $\begin{array}{l}\text { serangan terdapat pada pentil buah } \\
\text { kakao }\end{array}$ \\
\hline 12. & G12 & menyerang pada tanaman muda \\
\hline 13. & G13 & tanaman menjadi gundul \\
\hline 14. & G14 & mnyerang daun muda \\
\hline 15. & G15 & $\begin{array}{l}\text { menyerang daun muda dan buah } \\
\text { muda kakao }\end{array}$ \\
\hline 16. & G16 & daun berubah menjadi kuning \\
\hline 17. & G17 & daunya kakao rontok \\
\hline 18. & G18 & menyerang buah kakao kecil \\
\hline 19 & G19 & $\begin{array}{l}\text { serangan mulai dari pangkal buah } \\
\text { kakao }\end{array}$ \\
\hline 20 & G20 & buah kering dan mati \\
\hline
\end{tabular}

Table gejala hama di antaranya id_gejala dan gejala hama.

\subsection{6 perancangan aturan system pakar}

Aturan Sistem Pakar Penyakit Tanaman

Kakao (Theobroma Cacao L.)

a) Aturan $1:$ JIKA idgp01 AND idgp02 AND idgp03 AND idgp04 THEN idp01.

b) Aturan 2 : JIKA idgp05 AND idgp06 THEN idp02

c) Aturan 3 : JIKA idgp07 AND idgp08 AND idgp9 AND idgp10 THEN idp03.

d) Aturan 4 : JIKA idgp11 AND idgp12 THEN idp04

e) Aturan 5 : JIKA idgp13 AND idgp14 AND idgp 15 THEN idp05

f) Aturan $6:$ JIKA idgp16 AND idgp17 AND idgp18 AND idgp19 THEN idp06.

g) Aturan 7 : JIKA idgp20 AND idgp21 AND idgp22 AND idgp23 AND idgp24 AND idgp25 AND idgp26 THEN idp07

h) Aturan $8:$ JIKA idgp27 AND idgp28 AND idgp29 AND idgp30 THEN idp08. 
3.4.7 Aturan Sistem Pakar Hama Tanaman Kakao

\begin{tabular}{|c|c|c|c|}
\hline $\begin{array}{c}\text { Id } \\
\text { Gejala }\end{array}$ & Gejala & MB & MD \\
\hline P1 & buah kakao yang terserang berceak coklat hitam & 0,3 & 0,7 \\
\hline $\mathrm{P} 2$ & timbul lapisan yang berwarna putih bertepung jemur & 0,2 & 0,8 \\
\hline P3 & Kulit batang agak berlekuk dan berwarna lebih gelap atau kehitam-hitama & 0,3 & 0,7 \\
\hline $\mathrm{P} 4$ & mengelembung bagian batang atau cabang & 0,2 & 0,8 \\
\hline P5 & di serang akan terdapat bercak-bercak kuning & 0,6 & 0,4 \\
\hline P6 & Jika daun di petik maka ada nokta bekas coklat pada daun bekas duduk & 0,4 & 0,6 \\
\hline P7 & Mula-mula daun tampak menguning, layu dan akhirnya gugur dan diikuiti kematian. & 0,6 & 0,4 \\
\hline P8 & benang-benang jamur yang berwarna cokelat & 0,15 & 0,5 \\
\hline P9 & butir-butir tanah terdapat hifa jamur berwarna cokelat & 0,15 & 0,5 \\
\hline P10 & Penularan terjadi dengan kontak langsung antara akar sakit dan sehat. & 0,1 & 0,9 \\
\hline P11 & Mula-mula daun tampak menguning, layu dan akhirnya gugur dan diikuiti kematian. & 0,6 & 0,4 \\
\hline P12 & $\begin{array}{l}\text { Penyakit akar putih terdapat benang-benang putih yang bercabang melekat pada } \\
\text { permukaan akar. }\end{array}$ & 0,3 & 0,7 \\
\hline P13 & Mula-mula daun tampak menguning, layu dan akhirnya gugur dan diikuiti kematian. & 0,1 & 0,9 \\
\hline P14 & Penyakit akar merah terdapat lapisan jamur berwarna merah atau coklat tua. & 0,6 & 0,4 \\
\hline P15 & infeksi jamur ini pertama kalai terjadi pada sisi bagaian bawah cabang & 0,3 & 0,7 \\
\hline P16 & membentuk kerak yang berwarna merah jambu & 0,1 & 0,9 \\
\hline P17. & $\begin{array}{l}\text { ujung dari cabang yang sakit, daun-daun layu mendadak dan banyak yang tetap melekat } \\
\text { pada cabang, meskipun sudah kering }\end{array}$ & 0,6 & 0,4 \\
\hline P18. & $\begin{array}{l}\text { Jamur akan berkembang terus dan akan membentuk piknidia yang berwarna merah tua } \\
\text { dan biasanya terdapat pada sisi yang lebih kering }\end{array}$ & 0,6 & 0,4 \\
\hline P19. & bintik-bintik coklat pada daun muda, bercak coklat yang tidak beraturan & 0,25 & 0,75 \\
\hline $\mathrm{P} 20$. & ranting gundul berbentuk seperti sapu & 0,5 & 0,5 \\
\hline $\mathrm{P} 21$. & sering berlanjut dengan mati & 0,2 & 0,8 \\
\hline $\mathrm{P} 22$. & $\begin{array}{l}\text { da buah : bintik-bintik coklat pada buah muda yang berkembang menjadi bercak coklat } \\
\text { berlekuk (Antraksone). }\end{array}$ & 0,15 & 0,85 \\
\hline $\mathrm{P} 23$. & buah muda yang terserang menjadi layu, kering, dan mengeriput. & 0,15 & 0,85 \\
\hline $\mathrm{P} 24$. & Serangan pada buah tua akan menyebabkan gejala busuk kering pada ujungnya. & 0.4 & 0.6 \\
\hline $\mathrm{P} 25$. & $\begin{array}{l}\text { Satu atau dua pada flus kedua atau ketiga di belakang titik tumbuh menguning secara } \\
\text { kas }\end{array}$ & 0,2 & 0,8 \\
\hline P26. & daun yang sakit akan gugur beberapa hari setelah menguning & 0,5 & 0,5 \\
\hline P27. & daun yang sakit akan gugur beberapa hari setelah menguning & 0,5 & 0,5 \\
\hline $\mathrm{P} 28$. & Pada ranting yang bersangkutan terjadi satu atau dua daun gugur, & 0,1 & 0,9 \\
\hline P29. & $\begin{array}{l}\text { bekas tangkai daun yang sudah di sayat,terlihat adanya tiga noktah yang berwarna coklat } \\
\text { kehitaman }\end{array}$ & 0,1 & 0,9 \\
\hline P30. & ranting mati dari ujung (dieback). & 0,5 & 0,5 \\
\hline
\end{tabular}

a) Aturan 1 : JIKA idgh01 AND idgh02 AND idgh03 AND idgh04 AND idgh05 THEN idh01.

b) Aturan 2 : JIKA idgh06 AND idgh07 AND idgh08 THEN idh02.

c) Aturan $3:$ JIKA idgh09 AND idgh10 AND idgh11 AND idgh12 THEN idh03.

d) Aturan $4:$ JIKA idgh13 AND idgh14 THEN idh04.

e) Aturan 5 : JIKA idgh15 AND idgh16 AND idgh17 THEN idh05.

f) Aturan $6:$ JIKA idgh18THEN idh06.

g) Aturan 7 : JIKA idgh19 AND idgh20 AND idgh21 THEN idh07.

h) Aturan $8:$ JIKA idgh22 AND idgh23 AND idgh24 THEN idh08.

\section{HASIL DAN PEMBAHASAN}

\subsection{Implementasi}

Tahap implementasi dan pengujian ini merupakan proses pengubahan yang telah dirancang sebelumnya menjadi sebuah aplikasi sistem pakar untuk diagnosis hama dan penyakit tanaman kakao dengan metode Dempster shafer dan Certainty Faktor

\subsubsection{Tampilan Konsultasi pakar user}

Menu diagnosis Dempster shafer untuk penyakit yang menampilkan id_penyakit dan gejala penyakit.

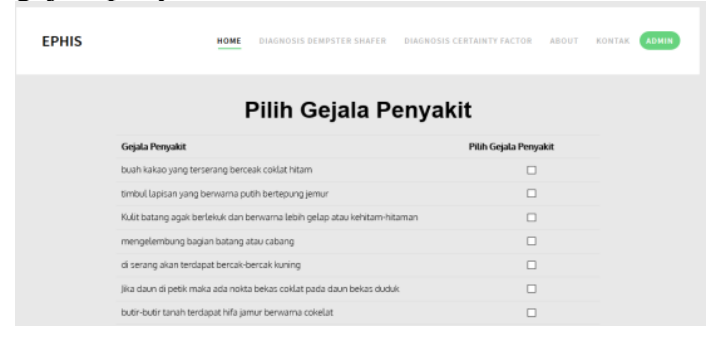

\subsubsection{Tampian Hasil Diagnosis user}

Menu tampilan untuk hasil dari diagnosis gejala penyakit . 


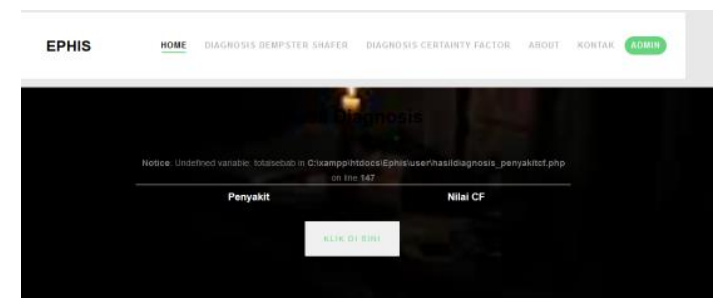

\subsubsection{Tampilan Kontak User}

Menu kontak user menampilkan informasi kontak dari admin yang mengelola website. Tampilan Kontak User

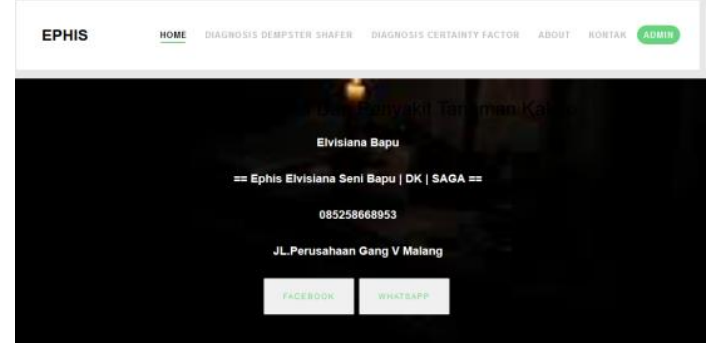

\subsection{Pengujian Sistem}

Pengujian merupakan tahap uji coba dari sistem yang dirancang dan di implementasikan kedalam sebuah aplikasi agar nantinya dapat diambil kesimpulan apakah sistem berjalan dengan baik sesuai tujuan awal pembuatan.

\subsubsection{Pengujian Sistem Admin}

Pengujian fungsional sistem dilakukan untuk menguji fitur-fitur yang ada pada website admin sistem pakar diagnosis hama dan penyakit tanaman kakao . Hasil Pengujian Sistem Admin dapat dilihat pada Tabel 4.1.

Dari hasil pengujian sistem admin menunjukkan bahwa fitur-fitur yang ada pada sistem dapat berjalan dengan baik.
Tabel 4.1 Pengujian Sistem Admin.

\begin{tabular}{|c|c|c|c|}
\hline \multirow[b]{2}{*}{ No } & \multirow[b]{2}{*}{ Modul (Fungsi) } & \multicolumn{2}{|c|}{ Browser } \\
\hline & & $\begin{array}{l}\text { Mozilla } \\
\text { Firefox }\end{array}$ & $\begin{array}{l}\text { Google } \\
\text { Chrome }\end{array}$ \\
\hline 1 & Login Admin & $\checkmark$ & $\checkmark$ \\
\hline 2 & Tambah Penyakit & $\checkmark$ & $\checkmark$ \\
\hline 3 & Edit Penyakit & $\checkmark$ & $\checkmark$ \\
\hline 4 & Hapus Penyakit & $\checkmark$ & $\checkmark$ \\
\hline 5 & Tambah Gejala & $\checkmark$ & $\checkmark$ \\
\hline 6 & Edit Gejala & $\checkmark$ & $\checkmark$ \\
\hline 7 & Hapus Gejala & $\checkmark$ & $\checkmark$ \\
\hline 8 & Logout Admin & $\sqrt{ }$ & $\checkmark$ \\
\hline
\end{tabular}

\subsubsection{Pengujian Fungsional User}

Pengujian fungsional sistem dilakukan untuk menguji fitur-fitur yang ada pada website user sistem pakar diagnosis hama dan Peyakit pada tanaman kakao berbasis website. Hasil Pengujian Sistem User dapat dilihat pada Tabel 4.2.

Tabel 4.2 Pengujian Sistem User.

\begin{tabular}{|c|c|c|c|}
\hline \multirow[b]{2}{*}{ No } & \multirow[b]{2}{*}{ Modul (Fungsi) } & \multicolumn{2}{|c|}{ Browser } \\
\hline & & $\begin{array}{l}\text { Mozilla } \\
\text { Firefox }\end{array}$ & $\begin{array}{l}\text { Google } \\
\text { Chrome }\end{array}$ \\
\hline 1 & $\begin{array}{l}\text { Konsultasi Pakar (Diagnosis } \\
\text { Ceratinty factor Gejala dan } \\
\text { Penyakit) }\end{array}$ & $\checkmark$ & $\checkmark$ \\
\hline 2 & $\begin{array}{l}\text { Konsultasi Pakar (Diagnosis } \\
\text { dempster Shafer Gejala dan } \\
\text { Penyakit) }\end{array}$ & $\checkmark$ & $\checkmark$ \\
\hline 3 & $\begin{array}{l}\text { Tampilan hasil diagnosis } \\
\text { Dempster Shafer }\end{array}$ & $\checkmark$ & $\checkmark$ \\
\hline 3 & $\begin{array}{l}\text { Konsultasi Pakar (Diagnosis } \\
\text { Certainty Factor Gejala dan } \\
\text { Penyakit) }\end{array}$ & $\checkmark$ & $\checkmark$ \\
\hline 4 & $\begin{array}{l}\text { Konsultasi Pakar (Diagnosis } \\
\text { Certainty Factor Gejala dan } \\
\text { Penyakit) }\end{array}$ & $\checkmark$ & $\checkmark$ \\
\hline 5 & Tampilan hasil diagnosi & $\checkmark$ & $\checkmark$ \\
\hline
\end{tabular}

Dari hasil pengujian sistem user menunjukkan bahwa fitur-fitur yang ada pada sistem dapat berjalan dengan baik.

\subsubsection{Analisis Perbandingan Metode Demspter Shafer Dan Certainty Faktor}

Tabel 4.3 Analisis Perbandingan hama Kakao

\begin{tabular}{|c|c|c|c|c|c|}
\hline No & penyakit & Metode & Sistem & Manual & Ket \\
\hline 1 & Penyakit Busuk Kakao & $\begin{array}{l}\text { CF } \\
\text { DS }\end{array}$ & Busuk Kakao & Busuk kakao & $\begin{array}{l}\text { OK } \\
\text { OK }\end{array}$ \\
\hline 2 & Penyakit Pembuluh Kayu & $\begin{array}{l}\text { CF } \\
\text { DS }\end{array}$ & Pembuluh Kayu & Pembuluh Kayu & $\begin{array}{l}\text { OK } \\
\text { OK }\end{array}$ \\
\hline 3 & Jamur akar Coklat & $\begin{array}{l}\text { CF } \\
\text { DS }\end{array}$ & Jamur Akar Coklat & Jamur Akar Coklat & $\begin{array}{l}\text { OK } \\
\text { OK }\end{array}$ \\
\hline 4 & Jamur Akar Putih & $\begin{array}{l}\text { CF } \\
\text { DS }\end{array}$ & Jamur Akar Putih & Jamur Akar Putih & $\begin{array}{l}\text { OK } \\
\text { OK }\end{array}$ \\
\hline 5 & Jamur Akar Merah & $\begin{array}{l}\text { CF } \\
\text { DS }\end{array}$ & Jamur Akar Merah & Jamur Akar Merah & $\begin{array}{l}\text { OK } \\
\text { OK }\end{array}$ \\
\hline 6 & Penyakit Jamur Upas & $\begin{array}{l}\text { CF } \\
\text { DS }\end{array}$ & Jamur Upas & Jamur Upas & $\begin{array}{l}\text { OK } \\
\text { OK }\end{array}$ \\
\hline 7 & Penyakit Atraknosis & $\begin{array}{l}\text { CF } \\
\text { DS }\end{array}$ & Penyakit Atraknosis & Penyakit Atraknosis & $\begin{array}{l}\text { OK } \\
\text { OK }\end{array}$ \\
\hline 8 & Penyakit VSD & $\begin{array}{l}\text { CF } \\
\text { DS }\end{array}$ & Penyakit VSD & Penyakit VSD & $\begin{array}{l}\text { OK } \\
\text { OK }\end{array}$ \\
\hline
\end{tabular}


Tabel 4.4 Analisis Perbandingan penyakit Kakao

\begin{tabular}{|c|c|c|c|c|c|}
\hline No & Hama & Metode & Sistem & Manual & Ket \\
\hline 1 & Pengerek Buah Kakao & $\begin{array}{l}\mathrm{CF} \\
\mathrm{DS}\end{array}$ & $\begin{array}{l}\text { Pengerek Buah } \\
\text { kakao }\end{array}$ & $\begin{array}{l}\text { Pengerek Buah } \\
\text { Kakao }\end{array}$ & $\begin{array}{l}\text { OK } \\
\text { OK }\end{array}$ \\
\hline 2 & Kepik Pengisap Buah & $\begin{array}{l}\text { CF } \\
\text { DS }\end{array}$ & $\begin{array}{l}\text { Kepik Pengisap } \\
\text { Buah }\end{array}$ & $\begin{array}{l}\text { Kepik Pengisap } \\
\text { Buah }\end{array}$ & $\begin{array}{l}\text { OK } \\
\text { OK }\end{array}$ \\
\hline 3 & $\begin{array}{l}\text { Pengerek Batang } \\
\text { Kakao }\end{array}$ & $\begin{array}{l}\text { CF } \\
\text { DS }\end{array}$ & $\begin{array}{l}\text { Pengerek Batang } \\
\text { Kakao }\end{array}$ & $\begin{array}{l}\text { Pengerek Batang } \\
\text { Kakao }\end{array}$ & $\begin{array}{l}\text { OK } \\
\text { OK }\end{array}$ \\
\hline 4 & Kelayuan Pentil & $\begin{array}{l}\text { CF } \\
\text { DS }\end{array}$ & Kelayuan Pentil & Kelayuan Pentil & $\begin{array}{l}\text { OK } \\
\text { OK }\end{array}$ \\
\hline 5 & Ulat Kilan & $\begin{array}{l}\text { CF } \\
\text { DS }\end{array}$ & Ulat Kilan & Ulat kilan & $\begin{array}{l}\text { OK } \\
\text { OK } \\
\end{array}$ \\
\hline 6 & Ulat Matahari & $\begin{array}{l}\text { CF } \\
\text { DS }\end{array}$ & Ulat Matahari & Ulat Matahari & $\begin{array}{l}\text { OK } \\
\text { OK }\end{array}$ \\
\hline 7 & Ulat Api & $\begin{array}{l}\text { CF } \\
\text { DS }\end{array}$ & Ulat Api & Ulat Api & $\begin{array}{l}\text { OK } \\
\text { OK }\end{array}$ \\
\hline 8 & Kutu Putih & $\begin{array}{l}\text { CF } \\
\text { DS } \\
\end{array}$ & $\begin{array}{l}\text { Kutu } \\
\text { Putih }\end{array}$ & Kutu Putih & $\begin{array}{l}\text { OK } \\
\text { OK } \\
\end{array}$ \\
\hline \multicolumn{6}{|c|}{$8 / 8 * 100 \%=100 \%$} \\
\hline
\end{tabular}

\section{KESIMPULAN DAN SARAN}

\subsection{Kesimpulan}

Berdasarkan hasil analisa dan pengujian yang telah dilakukan maka dapat di ambil beberapa kesimpulan antara lain :

1. Secara fungsional sistem ini dapat berjalan dengan baik dibeberapa web browser yaitu Mozila Firefox $=100 \%$, Chrome $=100 \%$ dan intenet explorer $=100 \%$

2. Berdasarkan analisis perbndingan metode Dempster Shafer dan Certainty factor menunjukan bahwa Dempster shafer lebih unggul dari Certainty Faktor.

\subsection{Saran}

Adapun saran yang perlu dikembangkan kedepannya agar lebih baik untuk pengguna aplikasi diagnosis hama dan penyakit pada tanaman kakao menggunakan metode dempster shafer dan certainty factor ini adalah :

1. Menambahkan beberapa tips untuk hama dan penyakit pada tanaman kakao.

2. Menambahkan form diskusi, sebagai media interaksi untuk pengunjung dan pakar.

3. Menambahkan beberapa hama dan penyakit beserta gejalanya.

\section{DAFTAR PUSTAKA}

[1] Okfalisa1, Yelfi Vitriani 2, M Fadhli Ihsan3, Fitri Insani4, Novi Yanti5, Frica A
Ambarwati6,Eggy P.13 November 2018 .Analisa Perbandingan Metode DempsterShafer (DS) Dan Certainty Factor (CF) Dalam Mendiagnosa Hama Dan Penyakit Kacang Tanah.

[2] Mugirahayu Handayani1, Taufiq2, Sistem Pakar Diagnosa Penyakit Tanaman Semangka Menggunakan Metode Dempster Shafer Berbasis WeB

[3] Amanda Patria Putra1, Cahya Rahmad2, Analisa Perbandingan Metode Certainty Factor Dan Dempster Shafer Pada Sistem Pakar Diagnosa Penyakit Diabetes Melitus

[4] 1Rizki Aptriani, 2Didik Kurniawan, 3Lestari Wibowo, Aplikasi Sistem Pakar Identifikasi Hama Dan Penyakit Serta Cara Pengendaliannya Pada Tanaman Kakao Berbasis Android

[5] Ririn Susanti1)Jusak2)Pantjawati Sudarmaningtyas3), Sistem Pakar Untuk Menentukan Penyakit Pada Tanaman Cokelat.

[6] Sitti Ardiantil, Umrah1 dan Asrul, Pengamatan Oncobasidium theobromae secara Makroskopis dan Mikroskopis, serta Gejala Serangan Sebagai penyebab Penyakit Vascular Streak Dieback (VSD) pada Tanaman Kakao di Kabupaten Sigi, Sulawesi Tengah.

[7] Arhami, M. (2005). Konsep Dasar Sistem Pakar. Yogyakarta: Penerbit Andi. 